\title{
Chairing the internal medicine department- analysis of current state and future trends in Israel
}

\author{
Dana Zelnik Yovel ${ }^{1 *}$ (D), Orna Tal', Dror Dicker ${ }^{1},{\text { Avishay } \text { Elis }^{3} \text { and Micha Rapoport }}^{1,4}$
}

\begin{abstract}
Background: Professional skills and academic records of the highest degree are essential requirements for the chairmanship of internal medicine departments. Whether the new generation and future successors of Israeli chairmen is endowed with these attributes is not known.

Purpose: To determine whether there is a lack of future suitable successors for the current heads of internal medicine departments in Israel and to compare the demographic, academic and professional characteristics of the older and newer generations of department heads.

Methods: An online anonymous questionnaire was nationally distributed during 2016 to all active heads of internal medicine departments in Israel $(n=101)$. First round was followed by two runs of personal phone calls to promote participation.

Results: Sixty-seven (67\%) of chairmen responded. The vast majority of current chairs of internal medicine departments are males $(N=59,88 \%)$ over 50 years of age $(N=58,86 \%)$ with established academic background with lecturer degree or higher $(N=57,85 \%)$.

Only 19 (28\%) of current heads assigned a future successor. Comparison of chairmen who did and did not assigned successors demonstrated that assignment of successors was associated with higher academic status $(P<0.02)$ and longer chairmanship $(p<0.01)$ but not with mean age of current chairmen $(p<0.08)$. Nevertheless, most assignments (55\%) were done by chairmen in the 61 to 67 years age group. As compared to current chairmen, the designated successors have lesser academic status $(p<0.01)$ and are characterized by a higher female prevalence $(P<0.03)$.

Conclusions: Significant demographic, professional and academic differences exist between the current chairs of internal medicine departments in Israeli hospitals and their future successors. This underscores the need for reassessment of the availability and requirements of this crucial position.
\end{abstract}

Keywords: Internal medicine, Chairman, Successor, Israel

\section{Introduction}

Internal medicine departments located in university affiliated medical centers are the training base for internal medicine specialists and the obligatory first phase preparation for the ensuing fellowships in the various sub-fields of internal medicine. They also serve as academic, research and teaching centers and as a

\footnotetext{
* Correspondence: danazelnik@gmail.com

"Department of internal medicine " $\mathrm{C}$ " at Assaf Harofeh Medical Center, Zerifin, Israel

Full list of author information is available at the end of the article
}

professional reference point to the medical community surrounding them.

Thus, professional skills, academic records of the highest degree and administrative skills are essential requirements that heads of these departments must have in order to fulfill their multiple deeds.

The prevailing albeit undocumented impression during the past decade in Israel is that candidates that have the desired combination of academic and professional skills have become "a rare breed", making it increasingly difficult to replace current heads of internal medicine departments with appropriate candidates. The reason (s) 
for the seemingly decreased candidate availability for these positions are not clear. It is possible that the ever-increasing administrative burden together with the recently growing shift of many medical practices from hospital to community significantly reduces the economic and professional rewards of hospital based position in general and head of internal medicine wards in particular. This notion is supported by Kastor et al. who conducted interviews with 44 current and former heads of internal medicine wards. They concluded that this position had lost much of its glory, in part because of increasing administrative and financial obligations that require more of the time and effort of department heads than before [1].

In order to verify this commonly held impression we determined for the 1st time whether there is a lack of future suitable candidates for the current heads of internal medicine departments in Israel. We also analyzed the characteristics of the present generation of department heads and compared them to the newer generation's characteristics. Our novel data demonstrates that although many wards assigned in advance a future chairman, the prototype of newer heads of internal medicine department is expected to change significantly.

\section{Methods}

\section{Study design}

Contact information was provided by the Israeli society of internal medicine. An online anonymous questionnaire was distributed on a national level to all active heads of internal medicine departments $(n=101)$. First round was followed by two runs of personal phone calls to promote participation. Data was collected using Google DOC application. Informed consent was obtained from all participants.

\section{Statistical analysis}

A chi test and $t$ test was performed to compare groups. $P$ value $<0.05$ was considered significant.

\section{Results}

Sixty seven of 101 (67\%) heads of internal medicine department answered the questionnaire. Analysis of current chairmen data demonstrated that chairmen were predominantly males (88\%), above the age of $50(86 \%)$, with a significant percentage (39\%) above 61 years, and the majority (85\%) having an academic rank of lecturer or above. The demographic and professional characteristic of these participants appear in Fig. 1.

Nineteen (28\%) current heads of departments confirmed the presence of a future successor, the majority of which 17 (89\%) came from the same departments or medical centers. As demonstrated in figure2, comparison of chairmen who did and did not assigned successors demonstrated that assignment of successors was associated with higher academic status $(P=0.016)$ and longer chairmanship $(p=<0.01)$. Although the percentage of chairmen above 50 years and above 61 years was higher in the group of chairmen who assigned successors, 79 and $55 \%$ and 58 and $32 \%$ respectively, these differences did not reach statistical significance $(p=0.08)$. Nevertheless, most assignments (55\%) were done by chairmen in the 61 to 67 years age group (Fig. 2).

As shown in Table 1, as compared to data of current chairmen upon their own appointment, designated successors are characterized by high prevalence of women and lower academic status. $(p=0.015)$.

In addition, fewer designated successors had a subspecialty degree, training time abroad and previous management experience although these differences did not reach statistical significance.

In an attempt to define the ideal future successor, we asked the 47 (70\%) current chairmen that did not have one nominated to indicate the most desired attributes of future successors. Forty-one (87\%) of current chairmen indicated that an academic position was of a significant importance in choosing a future successor, 29 (61\%) declared that it's important for them that the candidate will come from their own hospital/department and 23 (50\%) declared that experience in working abroad and previous management record are important.

We next compared the newer generation namely the assigned successor group $(N=19,28 \%)$ together with the less than 5 years in office current chairmen $(N=27$, $35 \%$ ) to the older generation of department heads with more than 5 years in office.

As shown in Table 2, there were no significant differences except a sub-specialty training was significantly more prevalent in the new as opposed to the old generation of chairmen $(P=0.001)$.

\section{Discussion}

This work describes for the first time in Israel the professional, demographic and academic attributes of current chairmen of internal medicine wards. More importantly, it provides novel national data regarding the availability and characteristics of future candidates who will likely replace current chairmen. These data are of outmost importance as chairmanship of these wards is long lasting, the newly assigned chairmen are expected to perform as the leaders of these wards as well as the professional and academic community in the next decades. The main outcome of our work is that times are indeed changing, and the newer generation of chairmen is significantly different as compared with the current one.

Our data underscore two major differences between the current generation of chairmen and the designated successors who have lesser academic degree and as a group have a higher prevalence of females. 

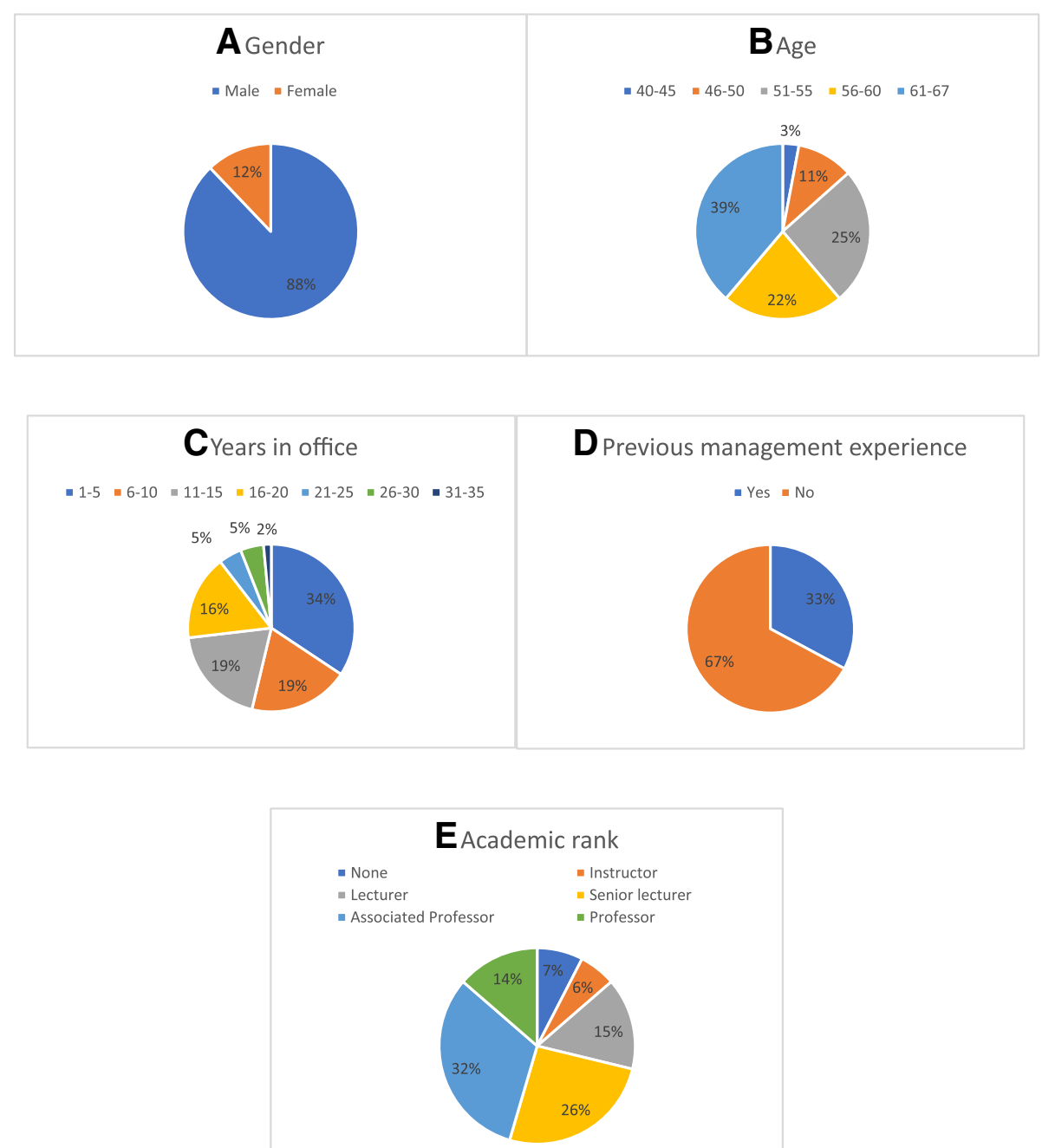

Fig. 1 Characteristic of current chairmen. Demographic and professional characteristic of current chairmen $n=77$ are presented: a Age, b Gender, c Years in office, d previous management experience e Academic Rank

Together with the observation that current heads with less than 5 years in office have as group lower academic ranks, they do support the currently held belief that these positions have been fulfilled with candidates of a lesser academic achievements, and this trend is likely to continue. It should be noted however, that the differences in academic rank became non-significant when not only successors but rather the new generation of chairmen, composed of successors and chairmen with less than 5 years in office were compared to the older generation chairmen (> 5 years in office). Nevertheless, these 2 groups still differed in their professional attributes namely sub-specialty training which was significantly more prevalent in the new generation of chairmen.

The importance of higher academic rank as an essential requirement for the chairmanship position is further underscored by the clearly expressed opinion of the vast majority current chairmen who established academic achievement as a first priority in choosing their future successor.

The reasons underlying these persistent gradual changes are not fully clear. Most probably, the increased administrative burden combined with the ever widening field of ambulatory medicine reduced the attractiveness of hospital based positions and provided increasingly more rewarding options out of hospital both economically and professionally $[2,3]$.

The higher prevalence of females among the new generation of department heads can be explained by the persistent increase of female predominance among medical students reaching over $60 \%$, according to Tel Aviv Sackler faculty of medicine data base. As well as the current composition of medical staff in the general medicine wards [4] allowing for more female candidates to compete for chairmanship positions [5]. This change takes place in spite of their higher levels of work-family conflict resulting in higher double burden than men [6]. 

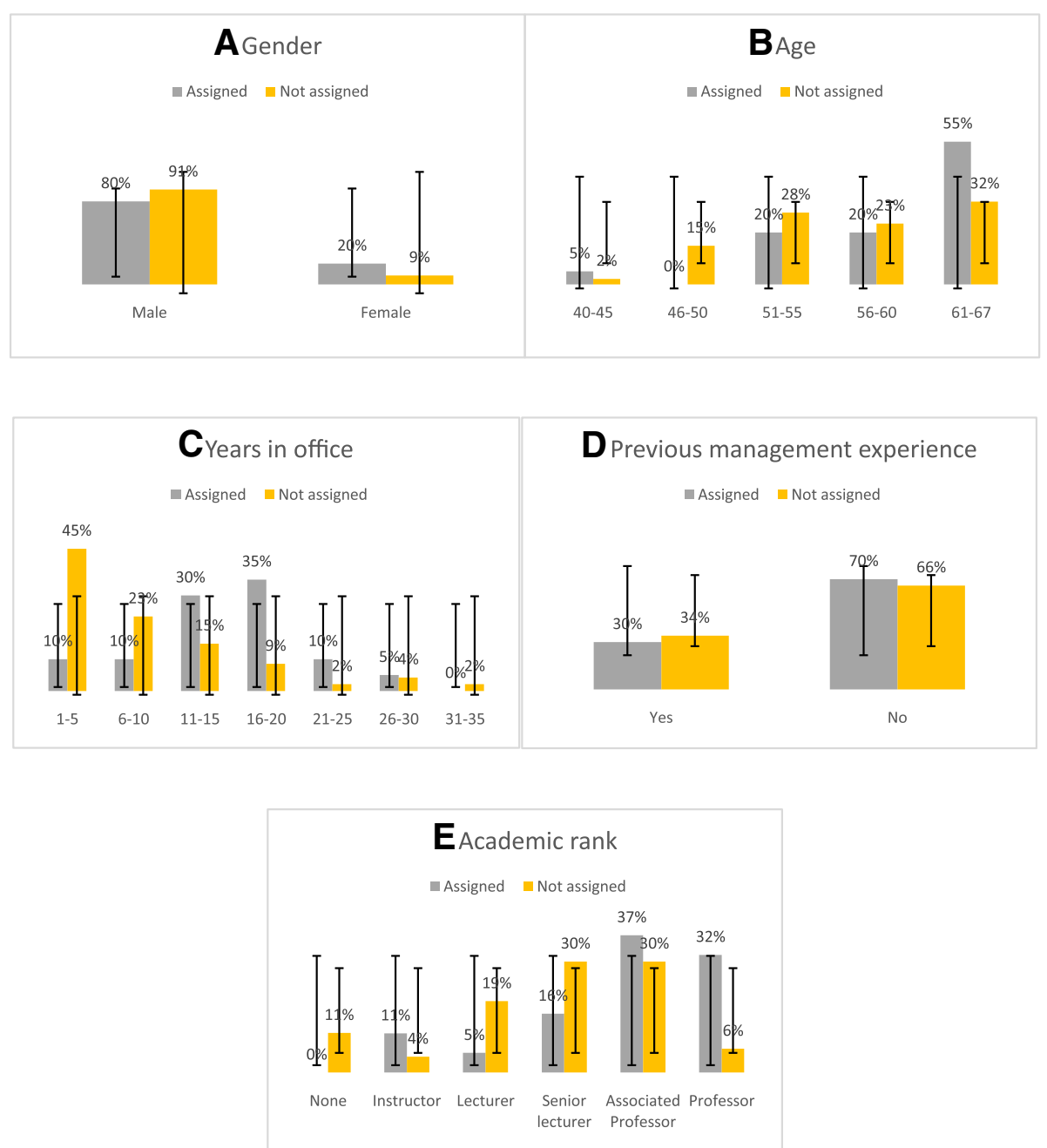

Fig. 2 Characteristic of chairmen who assigned successors and those who did not. Demographic and professional characteristic of current chairmen who did $(n=19)$ and did not assign $(n=47)$ are presented: Data represent mean $+/-$ Std $\mathbf{a}$ Age, $\mathbf{b}$ Gender, $\mathbf{c}$ Years in office, $\mathbf{d}$ previous management experience e Academic Rank.* $P<0.001{ }^{*} P<0.02$

Taken together these evolving trends initiate and maintain the gradual change observed in the attributes of new chairmen of internal medicine wards.

These observed trends are not limited to the Israeli medical community and most likely represent a worldwide trend. Similar but not identical findings were reported by Rayborn et al. demonstrating increased prevalence of women among $1^{\text {st }}$ time new chairs in 29 years perspective on recruitment and retention of department chairs in at U.S. medical schools [7]. These new chairs were however older as compared to former ones. Similarly to our findings, Heitz et al, in a survey of

Table 1 Demographic and professional characteristic of current chairmen of internal medicine departments and their designated successors

\begin{tabular}{llll}
\hline & Current heads n/\% & Designated successors n/\% & $P$ value \\
\hline Age $>50$ years upon appointment & $(22 / 65) 34 \%$ & $(6 / 16) 37 \%$ & 0.8 \\
Gender (male) & $(58 / 67) 88 \%$ & $(11 / 17) 65 \%$ & 0.03 \\
Academic rank of Lecturer or above upon appointment & $(51 / 64) 80 \%$ & $(8 / 16) 50 \%$ & $<0.01$ \\
Previous management experience & $(22 / 67) 33 \%$ & $(5 / 17) 29 \%$ & 0.7 \\
Subspecialty & $(40 / 58) 69 \%$ & $(7 / 13) 54 \%$ & 0.24 \\
Training time abroad & $(35 / 67) 53 \%$ & $(6 / 17) 35 \%$ & 0.17 \\
\hline
\end{tabular}


Table 2 Demographic and professional characteristic of *older and ${ }^{* *}$ newer generations of department's chairmen

\begin{tabular}{llll}
\hline & Old generation n/\% & Future generation n/\% & P value \\
\hline Age upon appointment & $(18 / 51) 35 \%$ & $(10 / 30) 33 \%$ & 0.85 \\
Gender (male) & $(39 / 44) 88 \%$ & $(31 / 40) 77 \%$ & 0.17 \\
Academic rank of Lecturer or above upon appointment & $(42 / 51) 82 \%$ & $(19 / 29) 65 \%$ & 0.08 \\
Previous management experience & $(12 / 44) 27 \%$ & $(15 / 40) 37 \%$ & 0.27 \\
Subspecialty & $(9 / 35) 25 \%$ & $(19 / 34) 55 \%$ & $<0.01$ \\
Training time abroad & $(25 / 43) 58 \%$ & $(16 / 40) 40 \%$ & 0.09 \\
\hline
\end{tabular}

$* 5$ years in office

** $<5$ years in office and appointed successors

current academic chairmen of emergency departments, found that, academic experience including scholarly productivity, peer-reviewed publication, faculty development, and graduate medical education, was the most important skill to obtain prior to becoming a chair, while hospital governance and cross-departmental collaboration skills can be obtained once in the role [8]. Finally, after interviewing 44 current and former chairs, deans, division chiefs, and hospital directors in the U.S., Kastor concluded that "the job of chair of a department of medicine, once seen as the apex in the career of an academic internist, has lost much of its allure, in part because of increasing administrative and financial obligations that require more of the time and effort of chairs than formerly" [1].

Our findings, in particularly those regarding the attributes of designated successors, should be interpreted with caution as much as it is not known what will be the age and academic rank of the designated successors upon assuming office. In addition, current chairmen can suggest and designate a potential candidate for chairmanship but by no mean have the official jurisdiction to appoint their successors or accurately predict when and if succession will effectively take place. The decision regarding succession is done by an official committee composed by several representatives who may prefer other candidates rather the designated successors. Thus, although there is no available data in that regard, it is conceivable that only a portion of the designated successors ultimately are appointed.

Nevertheless, our data together with similar trends observed worldwide provide valuable insights regarding the changing world of internal medicine chairmanship. Most importantly, it strongly suggests that it is mandatory that the leaders of public health who are in charge of planning future health policies and medical education including ministry of health, deans of medical schools, the internal medicine professional associations and hospital directors should all be aware of these change and act accordingly. Indeed, due to the current shortage of senior academic positions in the affiliated teaching wards the Tel Aviv faculty of medicine has recently initiated an academic hospital affiliation allowing non-fully academic wards to participate in medical students teaching.

\section{Conclusion}

Significant demographic, professional and academic differences exist between the current chairs of internal medicine departments in Israeli hospitals and their future successors. These significant differences underscore the need for reassessment of the needs and requirements of this crucial position.

\section{Acknowledgements \\ Not applicable. \\ Funding \\ none. \\ Availability of data and materials \\ The datasets used and/or analyzed during the current study are available from the corresponding author on reasonable request.}

\section{Authors' contributions}

DYZ- analyzed and interpreted the data. Major contributor in writing the manuscript. OT- major contributor in writing the manuscript. DD - Assisted in data collection and contributed to the writing of the manuscript. AEAssisted in data collection and contributed to the writing of the manuscript. MR- initiated, supervised and wrote the manuscript. All authors read and approved the final manuscript.

\section{Ethics approval and consent to participate}

Not applicable. No ethical approval was requested for this study by the local ethical committee.

\section{Consent for publication}

Not applicable.

\section{Competing interests}

The authors declare that they have no competing interests.

\section{Publisher's Note}

Springer Nature remains neutral with regard to jurisdictional claims in published maps and institutional affiliations.

\section{Author details}

"Department of internal medicine " $\mathrm{C}$ " at Assaf Harofeh Medical Center, Zerifin, Israel. ${ }^{2}$ Department "D" of internal Medicine at Hasharon Hospital Rabin Medical Center, Petah Tikva, Israel. ${ }^{3}$ Department " $\mathrm{C}$ " of internal at Belinson Hospital Rabin Medical Center, Petah Tikva, Israel. ${ }^{4}$ Sackler School of Medicine Tel-Aviv University, Tel Aviv, Israel.

Received: 12 September 2017 Accepted: 3 December 2018

Published online: 19 December 2018

\section{References}

1. Kastor JA. Chair of department of medicine now a different job. Acad Med. 2013;88(7):912-3. 
2. Grigsby RK, Kirch DG. The future-oriented department chair. Acad med. 2004;79(6):571-7.

3. Spehar I, Frich JC, Kjekshus LE. Clinicians' experiences of becoming a clinical manager: a qualitative study. BMC Health ServRes. 2012.

4. Haklai Z, Applbaum Y, Tal O, Aburbeh M, Goldberger NF. Female physicians: trends and likely impacts on healthcare in Israel. Isr I Health Policy Res. 2013;2(1):37

5. Isaac C, Griffin L, Carnes M. A qualitative study of faculty members' views of women chairs. J Womens Health. 2010;19(3):533-46.

6. Nilsen W, Skipstein A. Examination of the double burden hypothesis-a systematic review of work-family conflict and sickness absence. EurJ public health. 2017;27(3):465-71.

7. WF R, Scott JL. First-time department chairs at US medical schools: a 29-year perspective on recruitment and retention. Acad Med. 2010;19(3):533-46.

8. Heitz C, Hamilton GC. The academic chair in emergency medicine: current demographics and survey results identifying the skills and characteristics desired for the role. Acad Emerg Med. 2011;18(9):981-7.

Ready to submit your research? Choose BMC and benefit from:

- fast, convenient online submission

- thorough peer review by experienced researchers in your field

- rapid publication on acceptance

- support for research data, including large and complex data types

- gold Open Access which fosters wider collaboration and increased citations

- maximum visibility for your research: over $100 \mathrm{M}$ website views per year

At BMC, research is always in progress.

Learn more biomedcentral.com/submissions 